\title{
Predictors of Willingness to Participate in Window-of-Opportunity Breast Trials
}

Kari B. Wisinski, MD; Adrienne Faerber, PhD; Stephanie Wagner, MD; Thomas C. Havighurst, MS; Jane A. McElroy, PhD; KyungMann Kim, PhD; and Howard H. Bailey, MD

Objective: We conducted a pilot survey to evaluate breast cancer patients' willingness to participate in a preoperative chemoprevention (ie, window-of-opportunity) study.

Design: A 27-question written survey was developed and administered to participants.

Setting: A breast cancer specialty clinic at the University of Wisconsin Hospital and Clinics.

Participants: 30 adult patients with newly diagnosed operable breast cancer participated after signing informed consent.

Methods: A convenience sample of 30 participants was recruited from July 2005 through January 2006. Participants were administered the survey in clinic. Univariate ordinal logistic regression models were used to identify predictors of willingness to participate in window-of-opportunity trials.

Results: Overall, $26.7 \%$ of respondents were willing to participate in a research trial between the time of breast cancer diagnosis and surgery. Univariate ordinal logistic regression models identified that women with a prior history of breast cancer $(P=0.060)$, prior research participation $(P=0.006)$, more education $(P=0.034)$, and self-reported breast cancer knowledge $(P=0.043)$ were more willing to participate. On average, women preferred to have surgery 7 days (range I-14) after their diagnosis, but the actual average wait time between diagnostic biopsy and surgery was 37.5 days (standard deviation $=23.4$ days ).

Conclusion: There is ample time before breast surgery to conduct preoperative window-ofopportunity trials. Interventions aimed at expanding patients' breast cancer knowledge may improve accrual to window-of-opportunity studies.

Keywords: Breast Cancer; Survey; Chemoprevention; Window-of-Opportunity

Wemoprevention agents are medications or vitamins taken to reduce the risk for development of a specific cancer. Early phase clinical research of chemoprevention agents has many unique challenges. In particular, the effect of a potential chemoprevention agent is ideally evaluated not only in normal tissue, but also in malignant tissue. At the same time, the usual parameters of pharmacokinetics, toxicity, and drug tolerance must be evaluated. As assessing target tissue for effect of the agent is a primary goal of these studies, one must also consider the best approach to obtain adequate tissue samples while limiting the amount of risk and discomfort to the study participant. Although study designs vary depending on the organ sites of interest, in breast cancer chemoprevention studies, the most common techniques for obtaining breast tissue in patients without a breast cancer diagnosis have included nipple aspiration,

Corresponding Author: Kari B. Wisinski, MD; Assistant Professor of Medicine; University of Wisconsin School of Medicine and Public Health; IIII Highland Avenue, Rm 6033; Wisconsin Institute for Medical Research; Madison, WI 53705-2275; Telephone: (608)262-2876; Fax: (608) 265-6905; Email: kbwisinski@medicine.wisc.edu

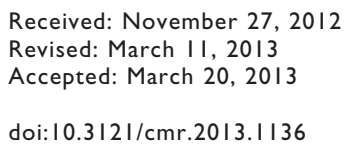

Grant support: Supported by grant IULIRR0250II from the Clinical and Translational Science Award (CTSA) program of the National Center for Research Resources, and P30 CAOI4520 National Institutes of Health, and the UW Carbone Cancer Center. 
ductal lavage, or four-quadrant fine needle aspirations. ${ }^{1}$ These techniques have varying strengths, but significant limitations of all of these techniques include the relatively low volume of cell/tissue retrieval, mixing of both normal epithelial cells and neoplastic cells (if present) during the collection procedure, and the limited stromal tissue acquisition. ${ }^{1-4}$

The treatment of solid tumors frequently involves a 2- to 6-week evaluation period between a diagnostic biopsy and the medically necessary surgical resection of the neoplasm, called the preoperative window. Research groups have leveraged the preoperative window for early phase studies of novel chemoprevention agents in various organs (ie, breast, prostate, and bladder). ${ }^{5-7}$ In these window-of-opportunity studies, patients receive study drug or placebo during the preoperative window. Then, at the time of the planned surgical resection of the identified neoplasm, extra neoplastic and normal tissues are obtained and subsequently analyzed for changes in surrogate endpoint biomarkers. While there are drawbacks to this window-of-opportunity approach, the main advantages are the ability to obtain relatively large sections of normal and neoplastic tissue that can be used for assessment of the chemoprevention agent's effects on multiple biomarkers. In addition, the researcher can obtain this tissue without exposing the participant to the risk and discomfort of an additional invasive procedure. This window-of-opportunity approach is also being used to study the biologic effect of new targeted agents for the treatment of various cancers. ${ }^{8-12}$ It is worthwhile to note that for chemoprevention agents, the access to pre-treatment normal and tumor tissue continues to be limited with this approach, as core biopsies are the mainstay for diagnosis for the majority of cancers. Thus, placebo-controlled studies are often utilized.

One common critique of the preoperative window-ofopportunity model is that it can lead to delays in potentially curative surgery that may affect survival outcomes. A review published in the International Journal of Clinical Practice ${ }^{13}$ summarized the published evidence about diagnostic evaluation leading to delays in breast cancer treatment. The review concluded that there was mixed evidence about whether delay in curative surgery may affect outcomes, but the main evidence supports that less than a 12-week delay has little to no effect on survival from breast cancer. However, one main issue with many of the reviewed studies was a failure to control for lead-time bias, which is the variability in delay between the patient detecting a symptom, presenting to the physician, diagnosis, and finally treatment. Another analysis specifically evaluating the impact of window-ofopportunity studies across multiple tumor types did not note any impact on survival. ${ }^{14}$ However, to limit any risk, windowof-opportunity clinical trial designs often incorporate a flexible treatment window to allow for variation in the surgical waiting period seen at different institutions and to enroll all participants who would take the minimum amount of treatment. Other designs may ask directly for a woman to delay surgery for a period while taking the study treatment for a fixed period of time.
Although early phase clinical research trials for preventive drug development is critical, enrollment of a sufficient number of eligible patients to preoperative early phase chemoprevention studies has been a challenge across many different tumor types. ${ }^{15}$ Barriers to participation are multiple and may include protocol requirements or exclusions, alternative therapeutic research studies excluding prior neoplastic therapies, concerns about delay of standard therapy, or because the participant is not interested in participating in the specific research study or any research study. Our own experience in preoperative chemoprevention trials for prostate and bladder cancer has observed approximately $10 \%$ of screened participants were subsequently enrolled in the trial. ${ }^{16}$ Several breast cancer window-of-opportunity trials have been conducted with novel chemopreventive agents. ${ }^{10,17-19}$ In these trials, the main factors that contribute to nonparticipation seem to be primarily related to protocol requirements or exclusions. However, also important to these studies are the large numbers of potential participants that are screened by recruiters or referred to the study but do not have any evidence of cancer in subsequent follow-up evaluations. In a preoperative trial of tamoxifen, $46 \%$ of screened potential participants with a suspicious mammogram did not have any evidence of cancer on a follow-up core biopsy. Only 1\% of screened patients were enrolled in this study. ${ }^{20}$

Thus, despite literature that supports window-of-opportunity studies as being safe and providing ideal access both to normal and tumor tissue, enrollment in these studies remains low. The purpose of this current study was to determine predictors of willingness to participate in a preoperative chemoprevention study at our center, the University of Wisconsin Carbone Cancer Center (UWCCC), using a prospective survey of women recently recommended to undergo curative breast surgery for breast neoplasia.

\section{Methods}

A 27-question written survey questionnaire was developed with the assistance of the Survey Research Core of the UWCCC. Participants were recruited from July 2005 through February 2006 at the Breast Center at the University of Wisconsin Hospital and Clinics in Madison, Wisconsin. The accrual goal of the study was 30 patients. A quota, convenience sample method was used due to our desire to evaluate the attitudes of breast cancer participants at the point of their diagnosis, instead of asking them to evaluate their own attitudes and beliefs retrospectively. Participant selection was not sequential. Participants were approached during the preoperative workup encounter for a pending lumpectomy or mastectomy, typically 2 to 3 weeks after the initial biopsy diagnosis of breast cancer and 7 to 10 days before planned definitive surgery. The eligibility criteria were a new diagnosis of breast cancer (in situ or invasive), recommendation for surgical intervention (mastectomy or lumpectomy), and age over 18 years.

The study was reviewed and approved by the Health Sciences Minimal Risk Institutional Review Board of the University of 
Table 1. Summary of participant $(n=30)$ demographics, medical status, and waiting periods.

\begin{tabular}{ll}
\hline $\begin{array}{l}\text { Demographics } \\
\text { White, non-Hispanic }\end{array}$ & $100 \%$ \\
Age (years) & 63 (range 48-82) \\
Education & $10 \%$ less than high school \\
& $30 \%$ completed high school \\
& $27 \%$ some college \\
& $33 \%$ college or higher \\
& $43 \%$ \\
Urban & $57 \%$ \\
Rural & 49.5 minutes (range $7.5-120$ ) \\
Travel time to the clinic & \\
(minutes) & \\
Breast Cancer Status & $33 \%$ DCIS \\
Neoplasm & $67 \%$ invasive carcinoma \\
& $67 \%$ lumpectomy \\
Surgery type & $33 \%$ mastectomy \\
Biopsy to surgery waiting & 37.5 (SD =23.4) \\
period (days) & \\
Preoperative workup & 11.3 (SD = 7.6) \\
encounter to surgery & \\
waiting period (days) & \\
\hline
\end{tabular}

DCIS, ductal carcinoma in situ

Wisconsin-Madison. All participants signed a written consent to participate in the survey study. The 27-question survey included socioeconomic variables (education level, local or rural residence, and household income), social support characteristics (relationship status, time and ease of travel to clinic, friends or family members with breast cancer), selfefficacy variables (breast cancer understanding and information seeking behaviors), previous participation in research studies, desired timeframe until surgery, and questions regarding willingness to participate in chemoprevention studies. We extracted information from the patient medical record including: cancer type, method of surgical intervention, date of diagnosis, date of surgery, and prior occurrence of breast cancer.

The primary objective of the survey study was to determine the predictors of willingness of newly diagnosed breast cancer patients to participate in a preoperative chemoprevention study. Secondary objectives included identification of a subset of patients who were more interested in participating based on medical or social characteristics, as well as evaluation of the perceived ideal timeframe from diagnosis to surgery compared to actual wait time.

Summary statistics such as proportion, mean \pm standard deviation (SD) or median (range) were used to describe the single-item responses. Ordinal logistic regression was performed using willingness to participate (willing, unsure/ needed more time, and unwilling) as the response variable. Univariate models are presented; because of the small sample size, $P$ value $<0.1$ was considered statistically significant.

\section{Results}

In total, 30 women completed the survey. All women who were approached to take the survey completed the survey. During the period from July 2005 through February 2006 a total of 73 women had a presurgical workup for an upcoming lumpectomy or mastectomy. We were unable to approach all of the women in the clinic due to staff coverage.

Patient demographics and breast cancer status are summarized in table 1 . The median age was 63 years. All women who participated in this trial were Caucasian, in part reflective of the demographic composition of patients at this institution. Participants self-reported their breast cancer knowledge as small $(27 \%)$, average $(52 \%)$, and large (21\%). Participants were asked about how soon they would schedule their surgery after they decided to have surgery if they had complete control, and the answer was, on average, 7 days (range 1 to 14 days). Review of the medical records from this cohort showed that the average duration between the preoperative clinic encounter and definitive surgery was 11.3 days, whereas the time between diagnostic biopsy to surgery was 37.5 days. This supports that there is an adequate period of time for window-of-opportunity studies. However, this small and nonrandom sample of participants may not reflect the overall waiting periods for our institution

When initially asked if they would be willing to participate in a chemoprevention study if offered, of the 26 participants who answered this question, $31 \%$ said yes; this represented $27 \%$ of the total survey population, as 4 participants did not answer this question. Of the remaining 18 participants, $19 \%$ were unsure, $31 \%$ needed more information to decide, and $19 \%$ said no. These numbers changed when asked about qualifying study parameters: $37 \%$ of participants stated they were more willing if a vitamin or food nutrient was the study drug, and $41 \%$ were more willing to participate if the study drug increased their immunity. There were mixed answers about willingness to participate if the study drug would lower cholesterol levels, was a hormone-like drug, a proven anticancer drug, or if the study had a placebo arm.

Table 2 summarizes the results from univariate ordinal logistic regressions with respect to willingness to participate. Willingness to participate, the dependent variable, was expressed as three levels, considered to be ordinal; not willing to participate, unsure about the decision or needing more information to decide, and willing to participate. The regression coefficient below is interpreted as the increase in $\log$ odds ratio of being in adjacent categories per unit increase in the variable in question. Significance of associations are based on the $\alpha=0.10$ level. 
Table 2. A summary of univariate ordinal logistic regressions. The dependent variable is self-reported willingness to participate in a breast cancer clinical trial between diagnostic biopsy and surgery.

\begin{tabular}{lcc}
\hline Variable & Regression Coefficient & $\boldsymbol{P}$ value \\
\hline Age & -0.047 & 0.242 \\
Log (age) & -3.071 & 0.226 \\
Breast cancer history & 2.379 & $0.060^{*}$ \\
Travel time & -0.014 & 0.225 \\
Log (travel time) & -0.860 & 0.117 \\
Difficulty of arrangements & 0.161 & 0.769 \\
Transportation reliability & -0.348 & 0.765 \\
Education & 0.693 & $0.034^{*}$ \\
Income & -0.118 & 0.682 \\
Relationship status & -0.414 & 0.590 \\
Breast cancer knowledge & 1.301 & $0.043^{\star}$ \\
Actively sought info & 0.539 & 0.608 \\
Number of sources used & 0.242 & 0.352 \\
Woman in family had cancer & 0.849 & 0.299 \\
Friends/Peers/Associates had cancer & -1.072 & 0.373 \\
How soon would you schedule surgery & -0.014 & 0.875 \\
Ever participated in any study & 3.275 & $0.006^{*}$ \\
\hline
\end{tabular}

*Statistically significant at the $\alpha=0.10$ level.

From this, we may infer that a personal history of breast cancer, higher education level, more personal knowledge about breast cancer, and prior study participation are factors that affect future willingness to participate in a chemoprevention clinical trial if offered.

\section{Recruitment Percent Calculation}

During the study timeframe (6 months), a total of 73 surgical preoperative patients were seen in the University of Wisconsin Hospital and Clinics Breast Center. Many of these would meet basic eligibility for a presurgical chemoprevention trial. Of those 73 women, 30 were approached and participated in our survey. Of those completing the survey, 8 (27\%) indicated they would be willing to participate in a preoperative study. Although this figure is a rough estimate due to the small sample size and the error surrounding the nonrandom sampling method, this suggests that over a 6-month period, approximately 20 participants would enroll in a window-ofopportunity study at our institution.

\section{Discussion}

The published literature supports the concept of pursuing preoperative breast chemoprevention trials, in that potential 1- to 4-week delays in curative breast surgery do not appear to adversely affect outcomes. ${ }^{14}$ Some research groups have successfully performed breast chemoprevention trials in this model, but barriers to patient enrollment in these studies remain. The primary endpoint of our survey study was to assess predictors of willingness of newly diagnosed breast cancer patients to participate in a theoretical presurgical breast chemoprevention window-of-opportunity study. We found that $8(27 \%)$ breast cancer participants surveyed said they would be interested; this is $9 \%$ of the total surgical patients seen in the breast clinic during our recruitment timeframe. This is consistent with our experience in prior or ongoing presurgical chemoprevention trials involving participants with recently diagnosed prostate or bladder cancer. However, our estimates are lower than the other measures presented in earlier research papers for accrual once eligibility was documented. ${ }^{5,8,19,21}$

Our survey investigated numerous factors that may impact a woman's decision to participate in preoperative chemoprevention trials. Our aim was to identify variables that may limit recruitment to these preoperative breast cancer chemoprevention studies. First, our survey questions were designed to help us potentially identify a sub-set of patients who would be more willing to participate. We found that the following parameters were associated with patients being more willing to participate: a prior diagnosis of breast cancer, prior participation in clinical research, higher education level, and self-reported large amount of knowledge about breast cancer. In order to potentially recruit women with prior diagnoses of breast cancer and prior participation in clinical research, protocol authors could keep these factors in mind when writing extensive exclusion criteria based on prior history and experimental therapies. Furthermore, early provision of accurate breast cancer and clinical trial resources may improve enrollment in these trials. This study also illustrates the need for institutions to develop comprehensive strategies for recruitment, including ways to identify eligible patients early, and prioritization of trials providing no direct 
benefit to participants recognizing they complement experimental treatment trials. Another key variable noted in our analysis was that patients were more willing to participate depending on the type of study drug used - vitamins and food nutrients as well as immune-boosting drugs were preferred.

To assess the feasibility of a window-of-opportunity breast cancer study, we assessed the wait time between diagnosis and surgery in the clinic to determine if there is an appropriate window in which to perform a study. We then compared this to the desired wait time of participants. We found that participants desired to have their surgery an average of 7.7 days after diagnostic biopsy and deciding to proceed with surgical therapy. In reality, 8 days is well below the average in the United States. Recent studies also suggest that wait times may be increasing after the introduction of breast magnetic resonance imaging into the diagnostic work-up..$^{22}$ In our study, the group of participants had a wait time average of 38.3 days. The actual wait time is greater than 4 weeks, which numerous presurgical chemoprevention studies use as a treatment period, so there is a "window-of-opportunity" present. The potential barrier is the perceived wait time from the participants' point-of-view and how that would affect recruitment. Timelines based on institution performance and discussions about lack of negative impact on survival from these wait times should be introduced earlier in the preoperative process. Thus, patients will not develop unrealistic expectations for the pace of treatment. This approach would not only benefit enrollment in preoperative studies, but also ensure adequate preoperative work-up of all cancer-related concerns (ie, contralateral breast imaging, evaluation of axillary lymph nodes, discussions regarding reconstructive options, and genetic counseling when indicated). While there has not been a randomized, controlled trial examining the effect of various durations from diagnosis to curative surgery on outcome, the reports support the oncologic dogma that modest delays in curative surgery do not affect outcome. There can still be other perceived negatives or actual risks to the potential participants considering preoperative chemoprevention studies. These include the possibility of the investigational chemoprevention agent adversely affecting peri- and post-operative risk (eg, increased bleeding or thromboembolic events) or having significant toxicity as an agent.

Generalizations from this study should be restricted due to the relatively small size, convenience sampling method and the limited diversity of our subject population. The study population was all Caucasian, which limits applying these results to other racial groups. Although studies have reported barriers to participation of minority subjects in chemoprevention studies, there is no data specifically for window-of-opportunity trials. ${ }^{23}$ Interestingly, there is data suggesting that in populations previously exposed to clinical research, African Americans are no less willing to participate in clinical trials than Caucasians. ${ }^{24}$ Due to the pilot nature of this survey, full validation of the survey instrument was not possible. Additional surveys of this type would need greater size and number of institutions in order to have greater validity. The experience of women before they present to the clinic is important when tying clinical research into the standard treatment plan. Earlier introduction to breast cancer and clinical trial resources may help women become more interested in this approach. Further studies to validate the findings from this study may benefit from an instrument administered at the time of mammography or biopsy.

\section{Conclusion}

Window-of-opportunity trials are critical in the development of cancer chemoprevention agents; yet, barriers to accrual to these studies have limited their widespread use. This study demonstrates that there is ample time between breast cancer diagnosis and primary breast surgery to conduct preoperative window-of-opportunity trials, and many women are willing to participate. Interventions aimed at expanding patients' breast cancer knowledge may improve accrual to these studies.

\section{Acknowledgements}

Linda Szalkucki, APNP, Mary Beth Henry, NP, and Heidi Walaski, NP assisted in recruiting participants. Kristin Mocadlo, PA, assisted with data management. Mary Hamielec assisted with IRB review and other administrative duties.

\section{References}

1. Fabian CJ, Kimler BF, Mayo MS, Khan SA. Breast-tissue sampling for risk assessment and prevention. Endocr Relat Cancer 2005; 12:185-213.

2. Arun B, Valero V, Logan C, Broglio K, Rivera E, Brewster A, Yin G, Green M, Kuerer H, Gong Y, Browne D, Hortobagyi GN, Sneige N. Comparison of ductal lavage and random periareolar fine needle aspiration as tissue acquisition methods in early breast cancer prevention trials. Clin Cancer Res 2007;13:4943-4948.

3. Dooley WC, Ljung BM, Veronesi U, Cazzaniga M, Elledge RM, O'Shaughnessy JA, Kuerer HM, Hung DT, Khan SA, Phillips RF, Ganz PA, Euhus DM, Esserman LJ, Haffty BG, King BL, Kelley MC, Anderson MM, Schmit PJ, Clark RR, Kass FC, Anderson BO, Troyan SL, Arias RD, Quiring JN, Love SM, Page DL, King EB. Ductal lavage for detection of cellular atypia in women at high risk for breast cancer. J Natl Cancer Inst 2001;93:1624-1632.

4. Khan SA, Masood S, Miller L, Numann PJ. Random fine needle aspiration of the breast of women at increased breast cancer risk and standard risk controls. The Breast Journal 1998:4:420-425.

5. Stearns V, Coop A, Singh B, Gallagher A, Yamauchi H, Lieberman R, Pennanen M, Trock B, Hayes DF, Ellis MJ. A pilot surrogate end point biomarker trial of perillyl alcohol in breast neoplasia. Clin Cancer Res 2004;10:7583-7591.

6. Iczkowski KA, Qiu J, Qian J, Somerville MC, Rittmaster RS, Andriole GL, Bostwick DG. The dual 5-alpha-reductase inhibitor dutasteride induces atrophic changes and decreases relative cancer volume in human prostate. Urology 2005;65:76-82.

7. Auman JT, Church R, Lee SY, Watson MA, Fleshman JW, McLeod HL. Celecoxib pre-treatment in human colorectal adenocarcinoma patients is associated with gene expression alterations suggestive of diminished cellular proliferation. Eur J Cancer 2008;44:1754-1760. 
8. Sooriakumaran P, Coley HM, Fox SB, Macanas-Pirard P, Lovell DP, Henderson A, Eden CG, Miller PD, Langley SE, Laing RW. A randomized controlled trial investigating the effects of celecoxib in patients with localized prostate cancer. Anticancer Res 2009;29:1483-1488.

9. Martin LA, Davies GL, Weigel MT, Betambeau N, Hills MJ, Salter J, Walsh G, A'Hern R, Dowsett M. Pre-surgical study of the biological effects of the selective cyclo-oxygenase-2 inhibitor celecoxib in patients with primary breast cancer. Breast Cancer Res Treat 2010;123:829-836.

10. Hadad S, Iwamoto T, Jordan L, Purdie C, Bray S, Baker L, Jellema G, Deharo S, Hardie DG, Pusztai L, MoulderThompson S, Dewar JA, Thompson AM. Evidence for biological effects of metformin in operable breast cancer: a pre-operative, window-of-opportunity, randomized trial. Breast Cancer Res Treat 2011;128:783-794.

11. Guix M, Granja Nde M, Meszoely I, Adkins TB, Wieman BM, Frierson KE, Sanchez V, Sanders ME, Grau AM, Mayer IA, Pestano G, Shyr Y, Muthuswamy S, Calvo B, Krontiras H, Krop IE, Kelley MC, Arteaga CL. Short preoperative treatment with erlotinib inhibits tumor cell proliferation in hormone receptor-positive breast cancers. J Clin Oncol 2008;26:897-906.

12. Carthon BC, Wolchok JD, Yuan J, Kamat A, Ng Tang DS, Sun J, Ku G, Troncoso P, Logothetis CJ, Allison JP, Sharma P. Preoperative CTLA-4 blockade: tolerability and immune monitoring in the setting of a presurgical clinical trial. Clin Cancer Res 2010;16:2861-2871.

13. Kothari A, Fentiman IS. Diagnostic delays in breast cancer and impact on survival. Int J Clin Pract 2003;57:200-203.

14. Glimelius B, Lahn M. Window-of-opportunity trials to evaluate clinical activity of new molecular entities in oncology. Ann Oncol 2011;22:1717-1725.

15. Tangrea JA. Patient participation and compliance in cancer chemoprevention trials: issues and concerns. Proc Soc Exp Biol Med 1997;216:260-265.

16. Messing E, Gee JR, Saltzstein DR, Kim K, diSant'Agnese PA, Kolesar J, Harris L, Faerber A, Havighurst TC, Young JM, Efros M, Getzenberg RH, Wheeler MA, Tangrea J, Parnes HL, House M, Busby JE, Hohl RJ, Bailey HH. A phase 2 cancer chemoprevention biomarker trial of isoflavone G-2535 (genistein) in presurgical bladder cancer patients. Cancer Prev Res (Phila) 2012;5:621-630.

17. Decensi A, Robertson C, Viale G, Pigatto F, Johansson H, Kisanga ER, Veronesi P, Torrisi R, Cazzaniga M, Mora S, Sandri MT, Pelosi G, Luini A, Goldhirsch A, Lien EA, Veronesi U. A randomized trial of low-dose tamoxifen on breast cancer proliferation and blood estrogenic biomarkers. J Natl Cancer Inst 2003;95:779-790.

18. Decensi A, Serrano D, Bonanni B, Cazzaniga M, GuerrieriGonzaga A. Breast cancer prevention trials using retinoids. J Mammary Gland Biol Neoplasia 2003;8:19-30.

19. Singletary E, Lieberman R, Atkinson N, Sneige N, Sahin A, Tolley S, Colchin M, Bevers T, Stelling C, Fornage B, Fritsche H, Hittelman W, Kelloff G, Lippman SM. Novel translational model for breast cancer chemoprevention study: accrual to a presurgical intervention with tamoxifen and $\mathrm{N}$-[4-hydroxyphenyl] retinamide. Cancer Epidemiol Biomarkers Prev 2000;9:1087-1090.

20. Singletary SE, Atkinson EN, Hoque A, Sneige N, Sahin AA, Fritsche HA Jr, Lotan R, Lu T, Hittelman WN, Bevers TB, Stelling CB, Lippman SM. Phase II clinical trial of N-(4Hydroxyphenyl)retinamide and tamoxifen administration before definitive surgery for breast neoplasia. Clin Cancer Res 2002;8:2835-2842.
21. Demark-Wahnefried W, George SL, Switzer BR, Snyder DC, Madden JF, Polascik TJ, Ruffin MTt, Vollmer RT. Overcoming challenges in designing and implementing a phase II randomized controlled trial using a presurgical model to test a dietary intervention in prostate cancer. Clin Trials 2008;5:262-272.

22. Bleicher RJ, Ciocca RM, Egleston BL, Sesa L, Evers K, Sigurdson ER, Morrow M. Association of routine pretreatment magnetic resonance imaging with time to surgery, mastectomy rate, and margin status. J Am Coll Surg 2009;209:180-187; quiz 294-295.

23. Grann VR, Jacobson JS, Troxel AB, Hershman D, Karp J, Myers C, Neugut AI. Barriers to minority participation in breast carcinoma prevention trials. Cancer 2005; 104:374-379.

24. Durant RW, Legedza AT, Marcantonio ER, Freeman MB, Landon BE. Willingness to participate in clinical trials among African Americans and whites previously exposed to clinical research. J Cult Divers 2011;18:8-19.

\section{Author Affiliations}

Kari B. Wisinski, $M D^{* *}$; Adrienne Faerber, $P h D^{* *}$; Stephanie Wagner, $M D^{* *}$; Thomas C. Havighurst, $M S^{* *}$; Jane A. McElroy, PhD $D^{* *}$; KyungMann Kim, PhD ${ }^{* *}$; and Howard H. Bailey, $M D^{* *}$

"University of Wisconsin School of Medicine and Public Health, Madison, Wisconsin

University of Wisconsin Carbone Cancer Center, Madison, Wisconsin 